\title{
Transcatheter Closure of Atrial Septal Defects
}

\author{
MARCELO AUSLENDER, M.D., ROBERT H. BEEKMAN, III, M.D., and THOMAS R. LLOYD, M.D. \\ From the Division of Pediatric Cardiology, Department of Pediatrics, C.S. Mott Children's Hospital, University of Michigan Medical \\ Center, Ann Arbor, Michigan
}

The first transcatheter closure of an atrial septal defect (ASD) was performed by King and Mills in 1976. The Lock Clamshell occluder and the buttoned device are the latest devices to undergo clinical trials. Successful transcatheter closure has been possible with minimal morbidity and mortality. Small residual shunts may remain, however, in up to $20 \%$ of patients 1 year after the procedure. The clinical significance and natural history of these small residual atrial communications remains to be determined. This article reviews the history and development of the current ASD closure techniques, with emphasis on the experience with the Lock Clamshell occluder and the buttoned device. (J Interven Cardiol 1995;8:533-542)

\section{Introduction}

The field of pediatric cardiac catheterization was expanded to its therapeutic potential in 1966 when Rashkind and Miller ${ }^{1}$ reported the first balloon atrial septostomy. Within a decade work was under way on techniques for catheter closure of atrial septal defects (ASDs). This article will revicw the history and development of the current ASD transcatheter closure techniques, with emphasis on the experience with the latest two devices: the Lock Clamshell occluder (USCI Angiographics, Tewksbury, MA, USA); and the buttoned device.

Pioneering ASD closure devices, in 1976 King et $\mathrm{al}^{2}{ }^{2}$ reported the first successful transcatheter closure of an ASD in humans. This original effort was performed in a 17-year-old female using an interlocking double-umbrella device made of stainless steel and Dacron delivered via a $22 \mathrm{Fr}$ catheter. A total of five patients underwent ASD closure with this device. ${ }^{3}$ The size of the delivery system and the fact that only defects $<20 \mathrm{~mm}$ in diameter could be closed were major

Address for reprints: Marcelo Auslender, M.D., Pediatric Cardiolagy, University of Michigan Medical Center, F1310 Maternal-Child Health Center, Box 0204, Ant Arbor, MI 48109-0204. Fax: (313) 936-9470. drawbacks. During the 1970s, Rashkind developed a transcatheter closure device for use in patients with a secundum type ASD. ${ }^{4}$ This device evolved to a singledisk occluder with hooks designed to anchor the system to the septal wall (Fig. 1A). In Rashkind's original human study, successful closure of the ASD was accomplished in 13 patients, but in six closure was not adequate. Failure was mainly due to inconsistent positioning of the device. Four patients required emergency surgery due to improper implantation of the device. ${ }^{4}$ Similar mixed results were reported by Beekman et al. ${ }^{5}$ These authors concluded that because of its anchoring hooks, the device could not be withdrawn into the delivery system or repositioned once advanced out of the delivery pod. Dislodgment from the atrial septum if all three hooks were not firmly attached to the atrial septal wall, as well as difficulties with the delivery system in positioning the device parallel to the atrial septum, were additional liabilities of the Rashkind devicc.

These experiences redirected development efforts in search of a self-centering device that could be retrieved into the delivery system if its initial position was unsatisfactory. Two new devices with some of these characteristics are presently being evaluated in clinical trials: the Lock Clamshell device (Figs. 1B and 1D); and the buttoned device (Fig. 1C). 

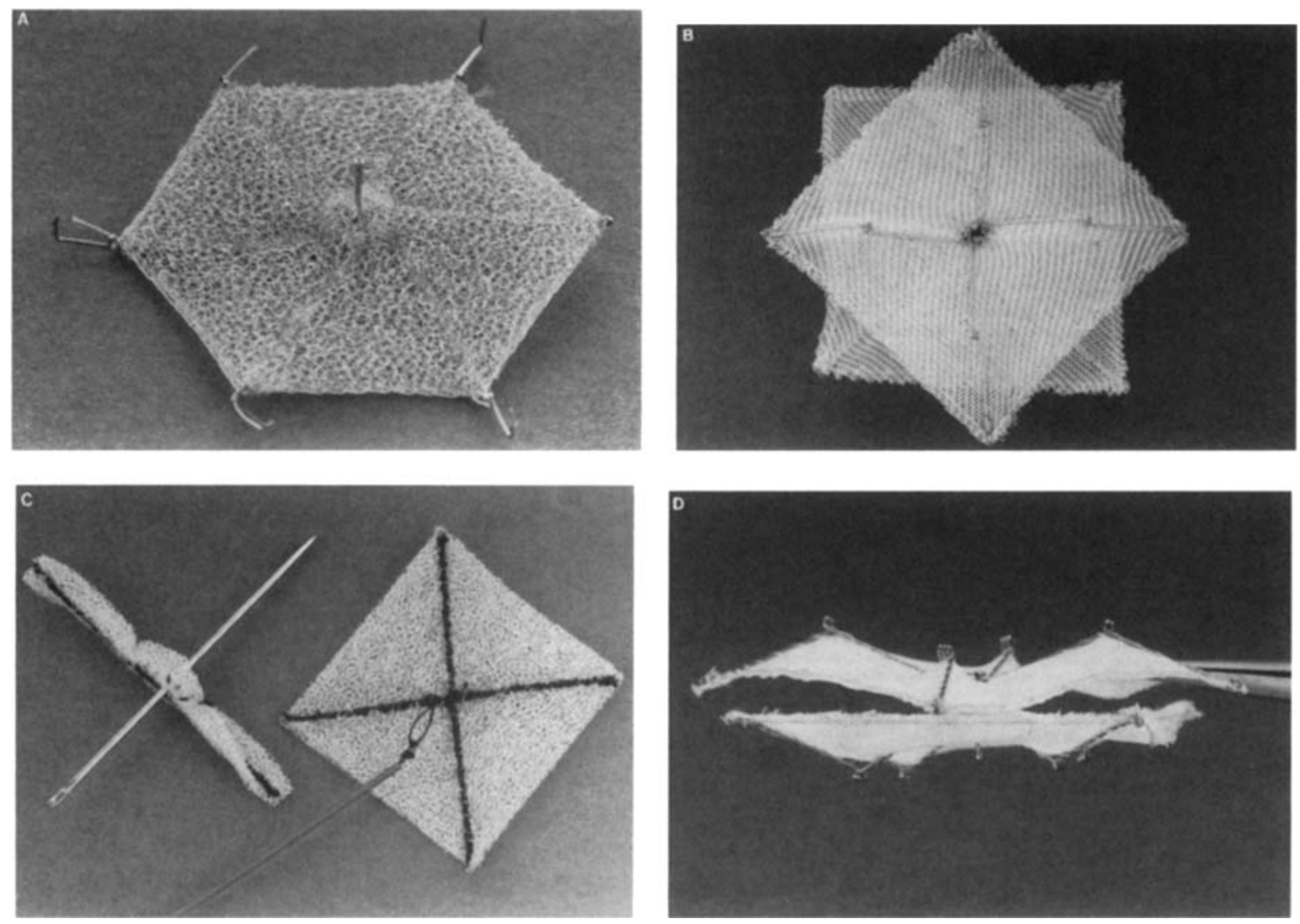

Figure 1. (A) Rashkind's hook fastened occluder. Three of the arms are hooked to anchor the device to the atrial septum. The prosthesis has six stainless steel arms that support a polyurethane foam disk. (B) Front and (D) profile of the Lock Clamshell device. Four steel arms provide the skeleton for the Dacron patch in each umbrella. The lateral view shows how the arms spring backward providing stability against the atrial septum. (C) The "buttoned" device. To the left the occluder's $\mathrm{X}$-shaped wire skeleton supports the polyurethane foam. Notice the button attached to the delivery wire. To the right the counter-occluder with a needle passed through the rubber piece which serves as the buttonhole.

\section{The New Generation of Atrial Septal Defect Closure Devices}

The Lock Clamshell Occluder. Disappointing results with the Rashkind single-umbrella hooked device led the Boston group to use the Rashkind PDA Occluder (USCI Angiographics) to close several types of heart defects, including some interatrial communications. ${ }^{6}$ This device combined the double-disk concept of King et al. ${ }^{3}$ with the small profile delivery system of the Rashkind hooked occluder.

Although the smaller delivery system and the lack of hooks were significant improvements, this device proved to be too small for the closure of most ASDs, and the umbrella design did not sufficiently promote apposition of the device edges to the atrial septum. The Lock Clamshell occluder (Figs. 1B and 1D) was designed to correct this problem by having the arms fold back against each other using spring tension, which fixes the device to the septum. ${ }^{6,7}$ During delivery, arm tension can be overcome, allowing for device centering and repositioning. The Clamshell device is made of two opposing umbrellas each composed of four steel arms; each arm is hinged at the center of the device and in the mid-portion of the arm. A woven Dacron patch is sewn to each umbrella. The device is currently available in diameters ranging from 17-40 $\mathrm{mm}$. The hinged arms are the major strength of the Clamshell occluder, but have also proved to be a weakness, with a number of instances of late arm fracture 
reported. Modifications have been made to correct this problem, and clinical trials of the improved Clamshell device are expected to begin soon.

The Buttoned Device. In 1990, Sideris et al. ${ }^{8}$ described their transcatheter ASD occlusion experience in piglets using a newly designed occlusion device: the buttoned double-disk device. It is composed of two parts, the occluder and the counter-occluder (Fig. 1C). The occluder is made of polyurethane foam, supported by a Teflon-coated wire skeleton that is $\mathrm{X}$-shaped when unfolded. A 2-mm string loop is attached to the center of the occluder, which is closed by a $1-\mathrm{mm}$ knot, the button. A second button in series has been added to the newest generation device to reduce the risk of unbuttoning, a complication observed in the earlier experiences. ${ }^{9}$ In addition, a radiopaque marker has been incorporated into the button for better visualization by fluoroscopy. The counter-occluder is a rhomboid-shaped piece of polyurethane foam containing a buttonhole made of rubber and a single Tefloncoated wire skeleton. The buttoned device is currently available in diameters ranging from $25-50 \mathrm{~mm}$. Reported experiences with these two devices are the basis of this review article.

\section{Patient Selection}

All investigators agree that the ASD of the secundum type is the most suitable for transcatheter closure due to its central location and circumferential rim of septal tissue. ${ }^{9,10}$ The devices should be at least twice the stretched diameter of the defect; consequently the largest defect currently amenable to transcatheter closure is approximately $20-25 \mathrm{~mm}$. It should also be emphasized that the defect must be sufficiently removed from neighboring cardiac structures that could be obstructed or distorted by the device (i.e., pulmonary veins, atrioventricular valves). The presence of multiple defects is not a contraindication for transcatheter closure, provided that the defects are close together enough so that positioning of the device through one defect ensures closure of the adjacent ones. ${ }^{10}$ In patients with a right-to-left shunt, the device-to-defect ratio must be larger due to a greater risk of systemic embolization. The Clamshell device is delivered via an 11 Fr sheath suitable for children weighing $>8-10$ $\mathrm{kg}$. The buttoned device requires an $8 \mathrm{Fr}$ or $9 \mathrm{Fr}$ sheath, making it more appropriate for younger children and also less traumatic on the femoral vessels.
Clinical indications for transcatheter ASD closure are the same as for surgical closure: atrial left-to-right shunts large enough to cause right ventricular overload; and patent foramen ovale (PFO) or small ASDs in patients at risk for paradoxical embolism.

Appropriate patient selection requires careful echocardiographic examination. Rao ${ }^{11}$ found that the stretched diameter of the ASD had better correlation with echocardiographic (ECHO) ASD diameter than with the angiographic size or Qp:Qs ratio. The formula stretched diameter $=1.05 \times \mathrm{ECHO}+5.49$ $\mathrm{mm}$ was validated in its ability to predict the stretched diameter with a correlation coefficient of 0.9 ( $\mathbf{P}<$ 0.001 ). In this study, two different views were used in order to detect defects with shapes other than circular. Averaging the diameter in two views minimized overestimation of the size of the defect.

\section{Diagnostic Catheterization and Device Delivery}

Routine pressure and oximetry measurements are performed to quantitate the left-to-right shunt and pulmonary artery pressure and resistance. Angiocardiography in a modified hepatoclavicular view $\left(45^{\circ}\right.$ left anterior oblique with $10^{\circ}$ cranial angulation) of the left atrium permits measurement of the ASD size and avoids foreshortening of the distance between the ASD and the orifice of the right upper pulmonary vein. ${ }^{10}$ The technique used to size the ASD has been welldescribed by several authors. ${ }^{3.6,12}$ A balloon-tipped catheter is advanced into the left atrium filled with diluted contrast material $(3: 1)$, and then withdrawn gently across the defect. Defects $<20 \mathrm{~mm}$ may be sized with a septostomy catheter or a 7Fr balloon endhole catheter, and larger defects are sized with an $8 \mathrm{Fr}$ occlusion balloon catheter (Meditech, Watertown, MA, USA). Care must be taken not to tear the rim of the defect and to find the minimum balloon size that completely occludes the ASD. The position of the balloon across the defect can be well-visualized with transesophageal echocardiography (TEE) (Fig. 2), and color flow Doppler is used to confirm that the balloon has completely eliminated the left-to-right shunting. TEE is also valuable in assessing the relationship of the ASD to neighboring structures, and in ruling out the presence of other ASDs (i.e., fenestrated septum). ${ }^{13,14}$ Closure of the ASD with the Clamshell oc- 


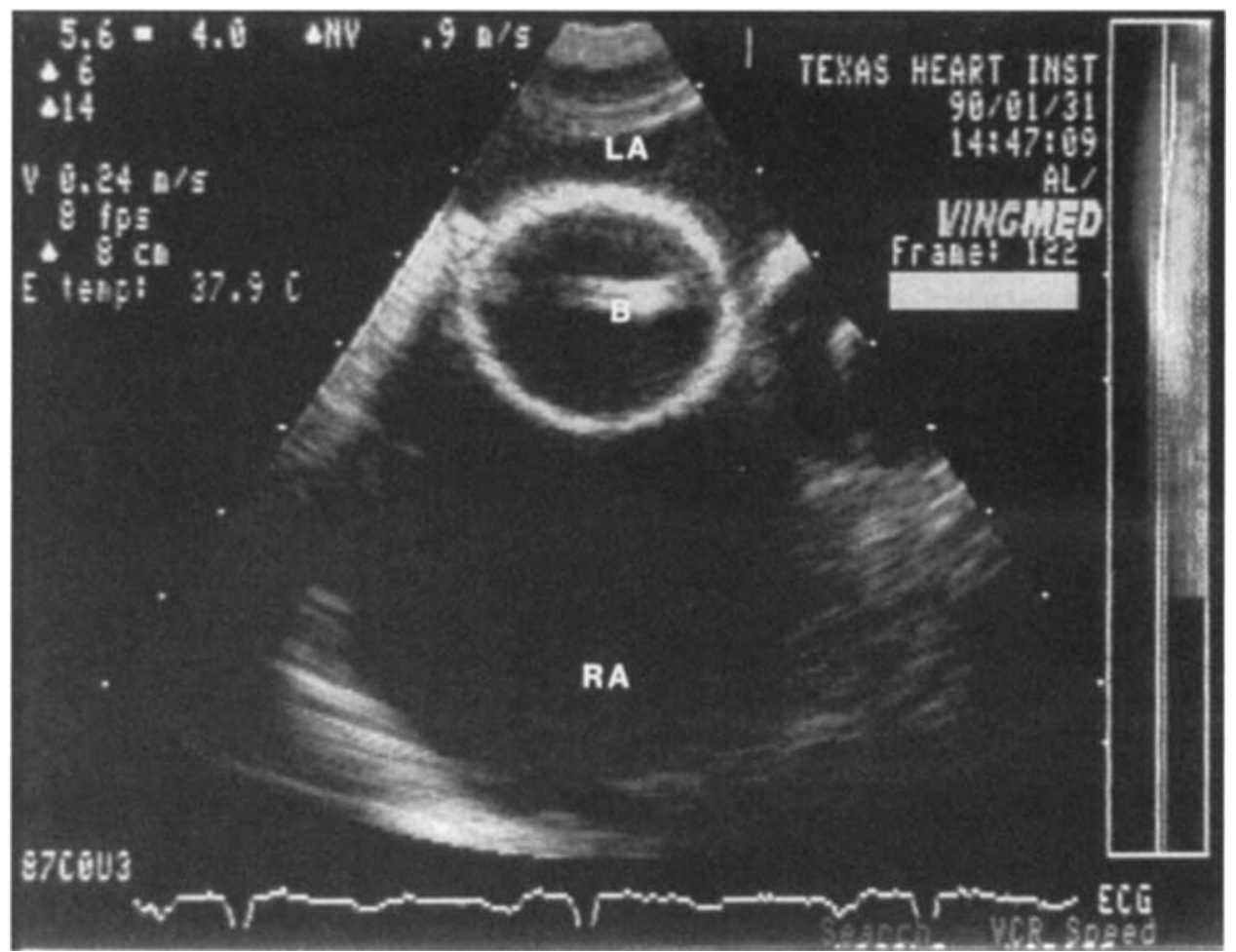

Figure 2. A balloon catheter can be seen across the atrial septal defect. The presence of residual shunting when sizing the "stretched diameter" of the defect can be visualized when color flow Doppler is applied. LA = left atrium; RA = right atrium. (With permission from the publisher.) $)^{14}$

cluder is attempted with a device that exceeds the stretched diameter of the defect by $70 \%$ in patients with left-to-right shunts, and by $80 \%-90 \%$ in those with significant right-to-left shunts. ${ }^{10}$ A $110 \%$ device to stretched diameter ratio is recommended for the buttoned device. No attempts have been reported to close right-to-left shunts with the buttoned device. Since the counter-occluder is smaller than the occluder, investigators have felt that patients with right-to-left shunts may be at higher risk for device embolization. A new buttoned device with a reversed design is being developed for this type of defect.

Delivery of the Clamshell Occluder. The delivery of the Clamshell device according to Lock's technique begins with the placement of an exchange wire across the defect and into the left upper pulmonary vein. $6,7,10$ An $11 \mathrm{Fr}$ sheath and dilator is then advanced into the left atrium (Fig. 3). During the subsequent withdrawal of the wire and dilator, special care must be taken to prevent air embolism. The device is then loaded into the sheath and advanced to the left atrium, allowing the distal arms to open freely and completely. With the right atrial umbrella still collapsed in the delivery sheath, both device and sheath are gently pulled back until the arms of the left atrial umbrella flex back, engaging the septal rim. The sheath is then withdrawn so that the proximal arms open in the right atrium. Given the acute angle between the atrial septum and the device, extra traction from the long sheath to force apposition of all four left atrial arms against the septal wall increases the risk for dislocation of the device across the defect. The device will self-center if the superior arms are securely engaged and the inferior arms are free as visualized by TEE. The device maintains an eccentric position while attached to the delivery system. This is responsible for significant residual shunts that may improve or disappear once the device has been released (Fig. 4A). ${ }^{10}$

Delivery of the Buttoned Device. The buttoned device requires an $8 \mathrm{Fr}$ long sheath (a 9Fr sheath is needed 


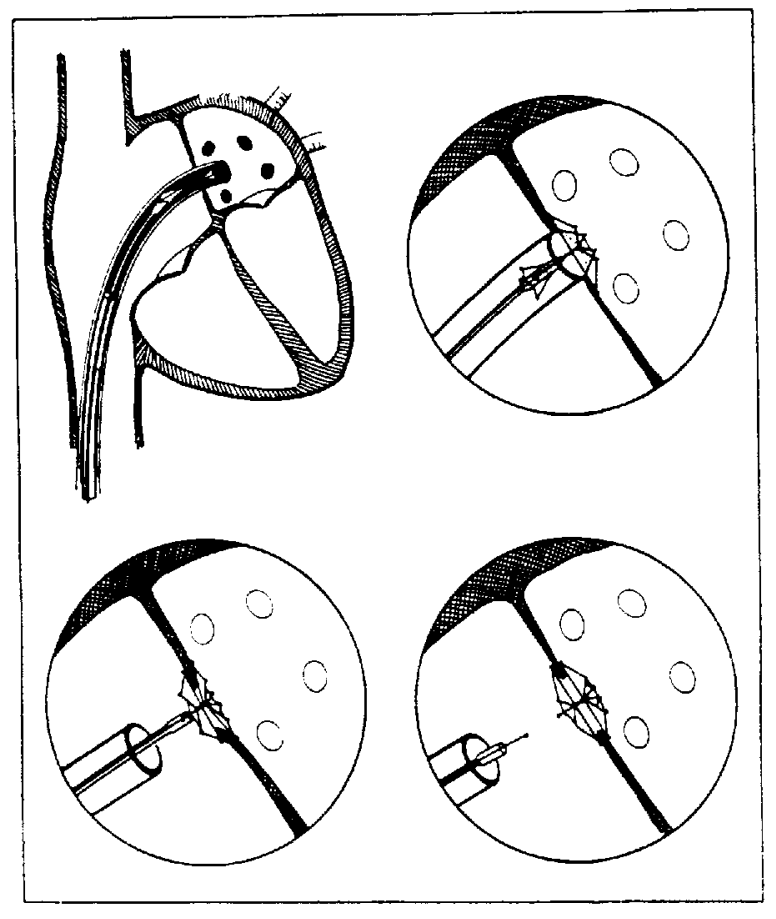

Figure 3. Diagram of the delivery of the Clamshell device. (With permission from the publisher) ${ }^{7}$ (see text for description.)

for 50-mm devices) positioned across the defect into the left atrium (Fig. 5) ${ }^{9,12}$ The occluder is then advanced into the left atrium with the help of an endhole catheter (pusher), which is inserted over the delivery wire. By gently withdrawing the delivery sheath, the occluder is freed in the left atrium, where it springs open and assumes its square shape (Fig. 5A). The occluder is pulled back against the atrial septum and the pusher catheter is withdrawn. The counter-occluder is now loaded by passing the delivery wire though the latex buttonhole. The pusher catheter is once again used to advance the counter-occluder through the sheath to the right atrium. Free in the right atrium, the counter-occluder assumes a position perpendicular to the sheath (Fig. 5B). While maintaining gentle traction on the delivery wire, and so keeping the occluder apposed to the left side of the septum, the counter-occluder is pushed to the right side of the septum by the delivery sheath (Fig. 5C). Further traction on the delivery wire and advancement of the sheath causes the button to pass through the button-hole, thus securing the system. The device is then released from the delivery wire (Fig. 4B, Fig. 5D).

\section{Results}

The Clamshell Occluder. In 1990 Rome et al. ${ }^{6}$ and Lock et al. ${ }^{7}$ published their initial clinical experience with four different double-umbrella devices for transcatheter closure of ASD. (A) The Rashkind PDA occluder $(\mathrm{n}=12)$; $(\mathrm{B})$ a modified PDA umbrella $(\mathrm{n}=$ 2); (C) a prototype Clamshell occluder ( $n=3)$; and (D) the Lock Clamshell occluder $(n=17) .{ }^{11}$ Out of 40 patients enrolled in the study, 34 had successful placement of the device, and 31 were discharged from the hospital with a device in place. Ages ranged from 10 months to 82 years. The anatomical lesions included 19 patients with secundum ASD, $3 \mathrm{PFO}, 3$ sinus venosus ASD, and the rest had complex heart defects with residual shunts after Fontan or Glenn procedures. ${ }^{10}$ Twenty-seven patients had a right-to-left and 11 had a left-to-right shunt. Echocardiographic studies at an average of 6 months after device placement were obtained in 19 patients. Twelve patients were found to have no residual shunts, 5 had periumbrella leaks, and in 2 patients a previously unrecognized additional ASD was found. Two patients suffered from device embolization. In the first case a device to diameter ratio of approximately $1: 6$ was utilized in a patient with right-to-left shunt. The second embolization occurred in a patient with a sinus venosus ASD.

There was one death in this study due to a cerebral embolus from a deep venous thrombus dislodged while advancing the delivery sheath. The conclusion from this heterogeneous group of patients and devices was that transcatheter closure of ASD is possible. The need for a complete rim of tissue for secure anchoring of the device, a larger device-to-stretched diameter ratio in patients with right-to-left shunt, and a $4-\mathrm{mm}$ separation between the ASD perimeter and neighboring cardiac structures became apparent.

In 1991, Latson et al. ${ }^{15}$ reported the results of a multicenter trial of the Clamshell device. Four hundred patients were enrolled in the clinical trial with ages ranging from 21 days to 78 years and weights ranging from $4.19-129 \mathrm{~kg}$. The clinical indications included: a significant left-to-right shunt $(\mathrm{n}-191)$; a right-toleft shunt $(\mathrm{n}=103)$; bidirectional shunts $(\mathrm{n}=69)$; or history of previous stroke $(n=8)$. Devices were placed and released in 393 cases. Follow-up echocardiographic evaluation at 1 month was available in 218 patients. In 71 pationts (33\%), small residual interatrial leaks were found. ${ }^{10}$ There were 28 complications $(7 \%)$, and 4 late deaths $(1 \%)$, none directly related to 


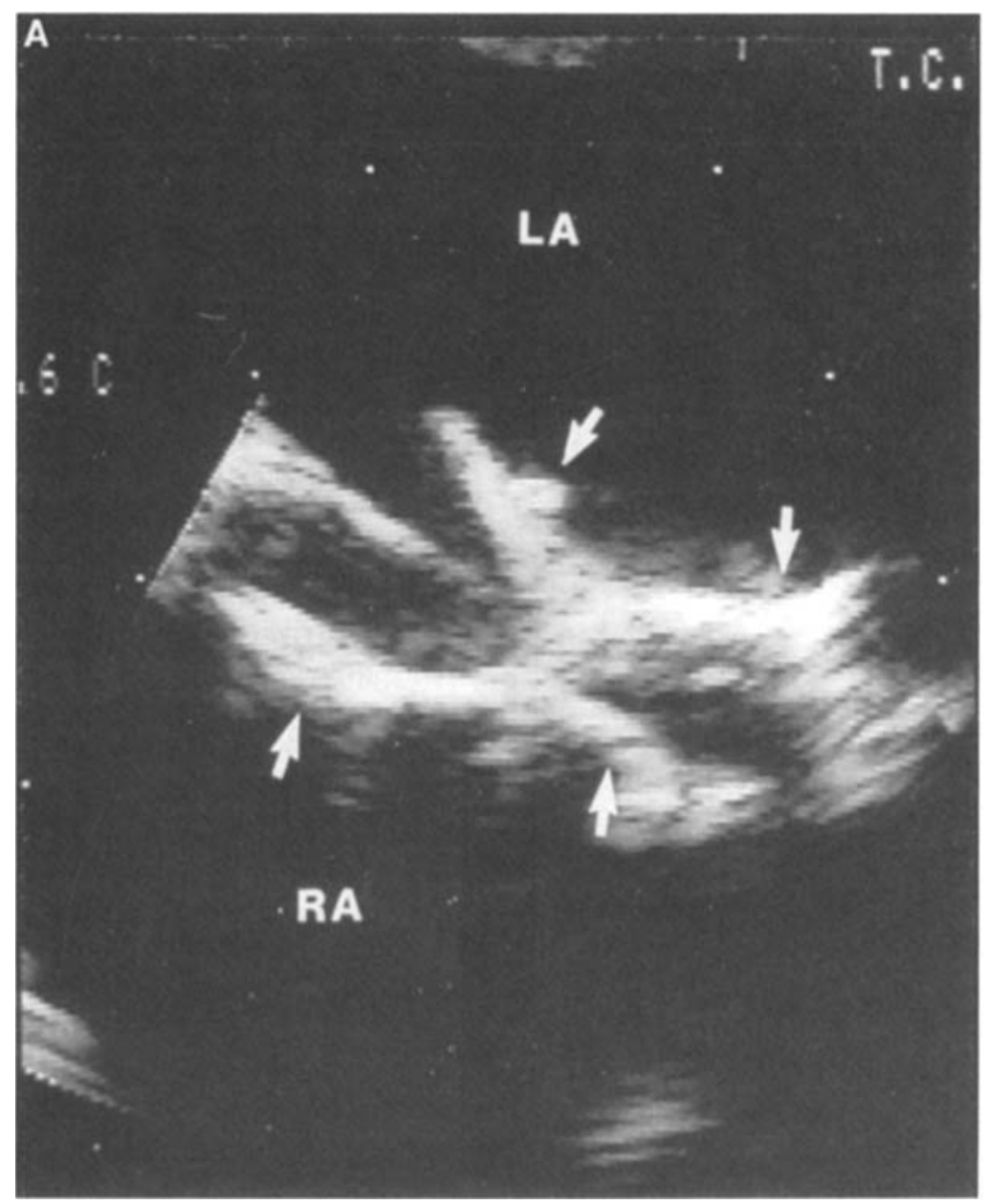

Figure 4. Transesophageal cchocardiographic images of (A) the Clamshell device (with permission from the publisher.) ${ }^{14}$

the procedure. In 17 patients (4\%), the device embolized after release. Eleven of these embolizations occurred upon release of the device and six becamc apparent during the month after placement. Two devices embolized to the right atrium, 3 to the right ventricle, 5 to the pulmonary artery, 2 to the left atrium, 1 to the left ventricle, and 4 to the aorta. Ten of these devices were retrieved by catheter techniques and 7 were removed surgically. In addition, 3 patients experienced systemic thromboemboli with stroke, 3 patients had air emboli, and 2 suffered vessel damage. ${ }^{10}$

More recent studies have reported use of the Clamshell occluder in other clinical scenarios: strokes associated with PFO and occlusion of Fontan baffle fenestrations. An association between stroke and the pres- ence of a PFO in young patients without any other identifiable etiology has been suggested by early reports and supported by recent TEE studies. ${ }^{16,17}$ In 1992, Bridges et al. ${ }^{18}$ reported their experience with transcatheter closure of PFO in such patients after presumed paradoxical thrombo-embolic stroke. Thirtysix patients underwent transcatheter closure of their ASDs. In 35 patients, the lesion was consistent with the morphological characteristics of a PFO; one patient had a true secundum type ASD. The average age was 39.4 years (median 39.1 years, range 1.4-64 years). The mean stretched diameter of the interatrial communication was $12.3 \mathrm{~mm}$. A Clamshell device was successfully placed in each case. One patient had multiple septal fenestrations that were occluded with a single 


\section{TRANSCATHETER CLOSURE OF ATRIAL SEPTAL DEFECTS}

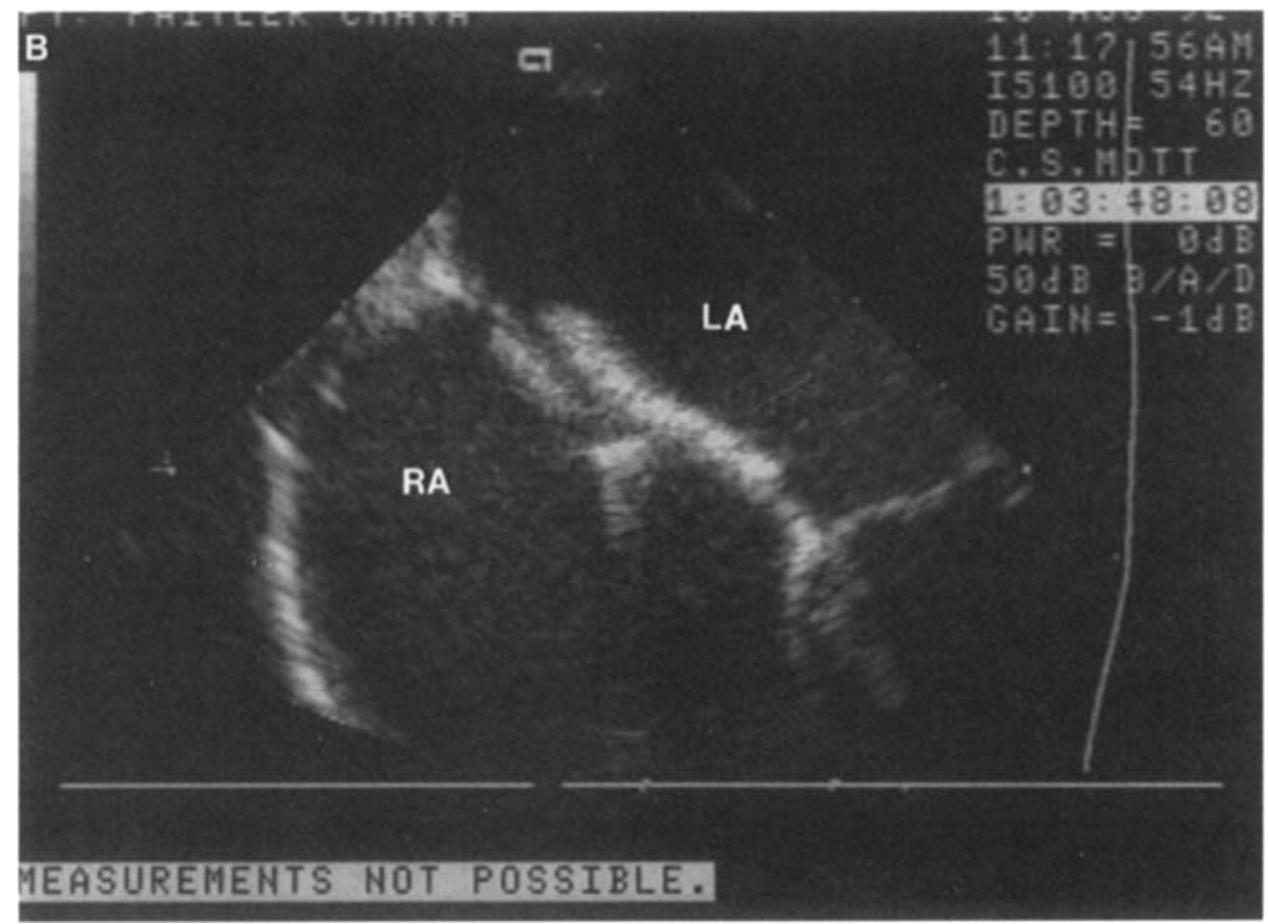

Figure 4. (continued) (B) the "buttoned" device, across the atrial septal defect once released from the delivery system.

device. Color Doppler studies showed complete closure of the PFO in 28 patients $(82 \%), 5$ had a $<1-\mathrm{mm}$ residual defect, and 1 patient had a $2-3-\mathrm{mm}$ residual defect. No new strokes were reported during a mean follow-up time of 8.4 months in 34 patients.

The baffle fenestration after the Fontan procedure was proposed as way of maintaining cardiac output via a right-to-left shunt for patients in whom pulmonary flow might be compromised in the early postoperative period. Bridges et al. ${ }^{19}$ reported their experience with transcatheter closure of such fenestrated Fontan baffles in the early postoperative period. This study reported 20 patients in whom a fenestrated Fontan procedure was performed because of the presence of at least one of the following: elevated pulmonary vascular resistance; a ventricular end diastolic pressure of $12 \mathrm{mmHg}$ or more; pulmonary artery distortion; mildto-moderate atrioventricular valve regurgitation; systemic ventricular outflow tract obstruction; and diminished ventricular systolic function and/or anomalous venous connection requiring concurrent surgical correction. The fenestration was closed at a postoperative cardiac catheterization if after 10 minutes of balloon occlusion there was no significant increase in right atrial pressure or decrease in right atrial saturation. Nineteen patients underwent a postoperative catheterization, and 11 patients underwent transcatheter closure of the fenestration with a $17-\mathrm{mm}$ Clamshell device (within 20 days of surgery). Color Doppler studies showed complete fenestration closures in ten and trivial residual leaks in two patients. The occlusion resulted in an acute decrease in cardiac output of $21 \%$, an increase in systemic oxygen saturation of $8 \%$, and an increase in mixed venous saturation of $2 \%$. Four patients failed carly fenestration occlusion due to a marked fall in cardiac output $(31 \%-56 \%)$. Three of these four patients underwent successful fenestration closure at a later date.

The Buttoned Device. In 1990, Sideris et al.$^{8}$ published the first report in which the buttoned device was used for transvenous ASD occlusion. The device was placed successfully in 17 piglets. Angiographic and color Doppler studies showed that the defects were fully closed. The devices were found to be endothelialized in 13 of 15 animals sacrificed 2 weeks or more after the procedure. ${ }^{8}$

Lloyd and colleagues ${ }^{9}$ reported in 1994 the multiinstitutional trial results of ASD occlusion with the 
A

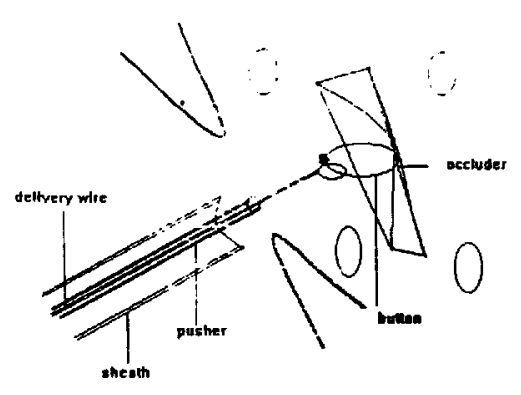

D

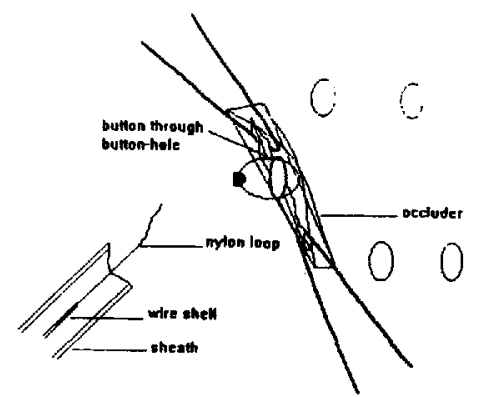

B

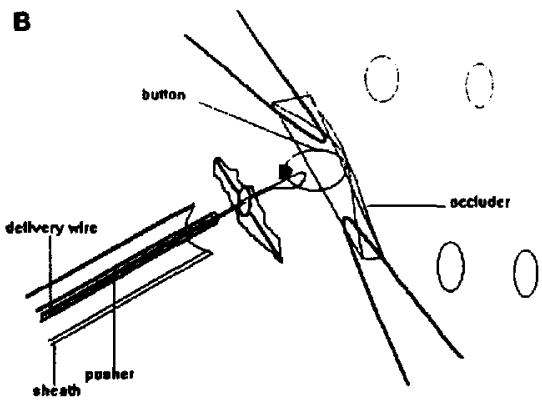

C

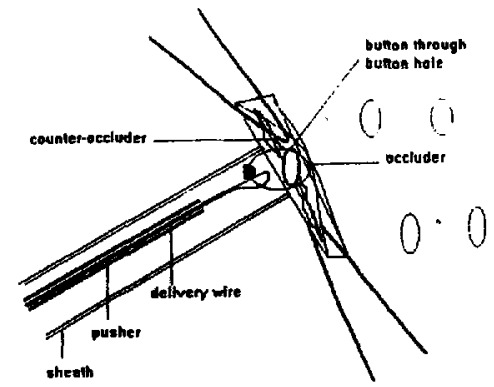

Figure 5. Diagram of the delivery of the "buttoned" device. (A) The occluder is released into the left atrium; (B) the occluder is pulled against the septal wall and the counter-occluder is released into the right atrium; (C) using the delivery sheath and holding gentle tension to the delivery wire the counter-occluder is advanced against the right atrial septal wall. Pulling gently the delivery wire the button is passed through the buttonhole securing the system; and (D) the device is released.

buttoned device. Fifty-seven patients were enrolled in this study. Forty-eight patients had a significant leftto-right shunt and nine had a persistent PFO and presumed paradoxical embolism. Ages and weights ranged from 1-62 years (median 4), and from 10-105 $\mathrm{kg}$ (median $18 \mathrm{~kg}$ ), respectively. Patients were excluded if other cardiac defects were present that would require surgical correction, if there was a dominant right-to-left shunt at the ASD level, if the stretched diameter of the defect was $>25 \mathrm{~mm}$, if there was insufficient rim of atrial tissuc to secure the device, and/or the iliofemoral veins or inferior vena cava were interrupted or obstructed.

Echocardiographic assistance was used to help guide device placement in 45 cases ( 32 transthoracic and 13 transesophageal). In 14 patients, percutaneous device removal was necessary before release from the delivery system. In eight of these patients a second device was successfully delivered, and in six patients further transcatheter occlusion attempts were aban- doned. Forty-six patients had successful implantation of the device. The stretched ASD diameter was $14 \pm$ $4 \mathrm{~mm}$ and Qp:Qs ratio before occlusion was $1.8 \pm$ 0.6. After placement of the buttoned device the $\mathrm{Qp}: \mathrm{Qs}$ ratio decreased to $1.1 \pm 0.2$ ( $\mathrm{P}<0.0001)$. Only 2 patients had a moderate residual shunt (Qp:Qs $1.5-2.0$ ).

The prevalence of small or moderate residual shunts as confirmed by color flow Doppler was $15 \%$ shortly after the procedure, $7 \% 1$ month after, $3 \%$ at 6 months, and $0 \%$ at 12 months. Twelve months after the procedure, $81 \%$ of the patients had no shunt detected by color flow Doppler and 19\% had only trivial residual shunts (Fig. 6). In four patients the device either "unbuttoned" or embolized from the atrial septum upon delivery or within the first 24 hours after release. In three patients the device "unbuttoned" with embolization of the counter-occluder to the low right atrium $(n=1)$ or to the distal pulmonary arteries $(n=2)$. In the fourth patient the entire device embolized into 


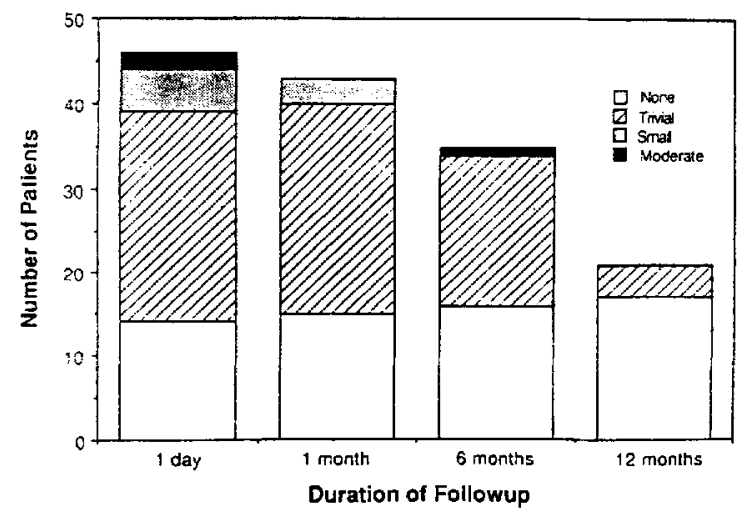

Figure 6. Residual shunts by clinical examination and Doppler echocardiography after implantation of the buttoned device. Open bars represent the number of patients with no shunt: hatched bars are the number of patients with trivial residual shunts; stippled bars are the number of patients with small residual shunts; solid bars are the number of patients with moderate residual shunts. The prevalence of residual shunts, which are of potential clinical significance (small or moderate), decreased from $15 \%$ immediately after implantation to $0 \%$ at 12 months. The prevalence of complete closure increased from $30 \%-81 \%$ at 12 months. Reduction in prevalence and size of residual shunts during follow-up was statistically significant $(\mathrm{P}<0.0001$, Spearman's rank correlation test). (With permission from the publisher. $)^{9}$

the main pulmonary artery upon release. All four devices were retrieved surgically and the ASD repaired without incident. There was one late "unbuttoning" with migration of the counter-occluder to the tricuspid valve that was discovered at 1-month follow-up. The authors point out that during this trial a button device with an eccentric radiopaque button was used. In the newer devices the button is less eccentric, and presently a new generation device with a double button for better lock between occluder and counter-occluder is under evaluation. These device modifications may diminish the incidence of unbuttoning in future cases.

\section{Discussion}

Since the early 1950s surgery has been the modality of choice for the treatment or palliation of patients with major congenital heart defects. Surgery for ASD in the current era has approached zero mortality and very low morbidity with negligible incremental risk factors regardless of ASD morphology or age. ${ }^{20}$ Over the last decade, parallel to the growth and sophistication in surgical techniques, the pediatric catheteriza- tion laboratory has expanded beyond its diagnostic role to include its therapeutic potential. Advances in minimally invasive transcatheter occlusion techniques have been made. The Clamshell double-umbrella and the buttoned device appear to provide effective therapies for the nonsurgical closure of ASD with a low degree of morbidity and mortality. In the multi-institutional trial, effective clinical closure of ostium secundum ASD $(<25 \mathrm{~mm}$ in diameter) was obtained in $98 \%$ of the patients in whom the buttoned device was successfully implanted. ${ }^{9}$ The experience with the Clamshell device showed similarly good results, with low morbidity and mortality. ${ }^{10,14}$

An ongoing concern is the presence of residual shunts after transcatheter ASD occlusion. Small residual shunts were found in $33 \%$ of the cases 1 month after ASD occlusion in the Clamshell multicenter experience, and in $19 \%$ of the patients 1 year after the buttoned device had been implanted. In contrast, a recent study found residual shunts in $7.8 \%$ of patients 4 months after surgical ASD repair. ${ }^{21}$ The clinical significance of these residual shunts remains unknown. In the buttoned device trial, the residual shunts were of no significant hemodynamic consequence, and there were no instances of bacterial endocarditis or systemic thromboembolism in 350 paticnt-months of followup. ${ }^{9}$ A cardiac catheterization was performed 6-12 months after occlusion in 11 patients with trivial residual shunts by color Doppler studies. In nine patients, no shunt could be detected by oximetry or angiography, and in two, trivial shunts were confirmed (Qp:Qs $<1.2)$.

Devicc embolization and device entrapment are the most serious complications encountered in the large clinical series of both devices, many of which could be managed in the catheterization laboratory without the need for cardiac surgery. Appropriate patient selection, improved device design, and increased operator experience may improve the already good results. Conditions required for effective transcatheter closure of ASD are: (1) an available device approximately twice the stretched diameter of the ASD (in patients with left-to-right shunts, devices $70 \%$ and $110 \%$ larger than the stretched diameter are recommended for the clamshell occluder and for the buttoned device, respectively); a larger device to stretched diameter ratio must be used for patients with right-to-left shunt; (2) the presence of a rim of atrial septal tissue appropriate for anchoring the occluding device; (3) the defect must be located at least $4-5 \mathrm{~mm}$ away from other neighboring cardiac structures; (4) a maximum stretched diameter 
of 20-25 mm; and (5) patent iliac veins and inferior vena cava without thrombotic disease. The presence of multiple defects is not a contraindication provided that the defects are sufficiently close together to ensure occlusion with a single device.

Large ASDs ( $>25 \mathrm{~mm}$ ) remain a challenge to transcatheter closure techniques. In this regard, Das et al. ${ }^{22}$ have described a newly designed double-disk device made of 2 outer pentagonal frames of nitinol wire covered with nylon or silk. The two disks are sewn together along a circumference the size of the ASD. This central oval area, together with the tension provided by the nitinol skeleton, reduces the mobility of the device along the atrial septum, and may prove useful for occlusion of the larger ASD.

Transcatheter closure of ASDs will likely prove to be a cost-effective treatment strategy. In two small series, a $60 \%-70 \%$ savings over the charges for surgical repair was found. ${ }^{23,24}$ At the University of Arizona, the hospital charges of 12 patients who underwent transcatheter occlusion of ASD were compared to the charges in 12 contemporaneous patients who underwent surgical closure of their ASDs. The median hospital charge for transcatheter occlusion was $\$ 6,193$ (range, $\$ 4,153-\$ 7,855$ ), a $72 \%$ savings over the median charge for surgical repair $(\$ 21,875)$ (range, $\$ 16,310-\$ 24,785)$. Transcatheter ASD occlusion was performed as an outpatient procedure in six patients and with a 1-day hospitalization period in 6 patients. In the surgical group the median hospitalization duration was 6 days (range 3-14 days). ${ }^{24}$

Transcatheter closure of ASD is an effective mode of therapy, although it remains investigational in 1995. Further research in device design is needed to reduce the incidence of residual shunt and to prevent dislodgment and embolic phenomena. Clinical trials are also necessary to document the efficacy of device closure of PFO in the prevention of thromboembolic strokes. If future clinical trials continue to document the efficacy, safety, and cost-effectiveness of transcatheter ASD occlusion, this less invasive approach is likely to replace surgery as the treatment of choice in this patient population.

\section{References}

1. Rashkind WJ, Miller WW. Creation of an atrial septal defect without thoracotomy: Palliative approach to complete transposition of the great arteries. JAMA 1966; 196:991-992.
2. King TD, Thompson SL, Steiner C, et al. Secundum atrial septal defect. Nonoperative closure during cardiac catheterization. JAMA 1976;235:2506-2509.

3. Mills NL, King TD. Nonoperative closure of left-to-right shunts. J Thorac Cardiovase Surg 1978;72:371-378.

4. Rashkind WJ. Transcatheter treatment of congenital heart disease. Circulation 1983;67:711-716.

5. Beekman RH III, Rocchini AP, Snider R, et al. Transcatheter atrial septal defect closure: Preliminary experience with the Rashkind occluder device. J Interven Cardiol 1989;2:35-41.

6. Rome JJ, Keane JF, Perry SB, et al. Double-umbrella closure of atrial defects. Initial clinical applications. Circulation 1990; 82:751-758.

7. Lock JE, Rome JJ, Davis R, et al. Transcatheter closure of atrial septal defects. Experimental studies. Circulation 1989; 79:1091-1099.

8. Sideris EB, Sideris SE, Fowlkes JP, et al. Transvenous atrial septal occlusion in piglets with a "buttoned" double-disk device. Circulation 1990;81:312-318.

9. Lloyd TR, Syamasundar Rao P, Beckman RH III, et al. Atrial septal defect occlusion with the buttoned device. (a multiinstitutional U.S. trial). Am J Cardiol 1994;73:286-291.

10. Rome JJ. Transcatheter closure of atrial septal defects. Prog Pediatr Cardiol 1992;12:63-71.

11. Rao P, Langhough R, Beekman RH III, et al. Echocardiographic estimation of balloon-stretched diameter of secundum atrial septal defect for transcatheter occlusion. Am Heart J 1992;124:172-175.

12. Rao P, Willson AD, Levy JM, et al. Role of the "buttoned" device in the management of atrial septal defects. Am Heart J 1992;123:191-200

13. Hellenbrand WE, Fahey JT, McGowan FX, et al. Transesophageal echocardiographic guidance of transcatheter closure of atrial septal defect. Am J Cardiol 1990;66:207-213.

14. Ludomirsky A. Transcatheter occlusion of atrial and ventricular septal defects. In: Stümper O, Sutherland GR, eds. Transesophageal Echocardiography in Congenital Heart Disease. Eduard Arnold, 1994, pp. 199-212.

15. Latson LA, Benson LN, Hellenbrand WE, et al. Transcatheter closure of ASD - early results of multicenter trial of the Bard clamshell occluder. Circulation 1991;84(Suppl):II-544.

16. De Belder M, Tourikis L, Leech G. Patent foramen ovale-risk factor for thromboembolic events in all age groups? Circulation 1990;82(Suppl):III-109.

17. Hausman D, Muegge A, Becht I, et al. Patent foramen ovale diagnosed by transesophageal echocardiography: High prevalence in young adults with stroke or peripheral embolism. (abstract) JACC 1991;17:143A

18. Bridges ND, Hellenbrand W, Latson L, et al. Transcatheter closure of the patent foramen ovale after presumed paradoxical embolism. Circulation 1992;86:1902-1908.

19. Bridges ND, Lock JE, Castaneda AR. Baffle fenestration with subsequent transcatheter closure. Circulation 1990;82: $1681-1689$.

20. Atrial septal defect and partial anomalous pulmonary venous connection. In: Kirklin, Barratt-Boyes, eds. Cardiac Surgery. Second edition. Churchill and Livingston, 1993, pp. 610-673.

21. Pastorek JS, Allen HD, Davis IT. Current outcomes of surgical closure of secundum atrial septal defect. Am J Cardiol 1994; 74:75-77.

22. Das GS, Jarvis G, Wyche $K$, et al. A new transcatheter atrial septal closure device. Circulation 1992;86(Suppl):I-633.

23. Bridges ND, Newburger JW, Mayer JE. Transcatheter closure of the secundum ASD in the pediatric patients: The first year's experience. (abstract) Am J Cardiol 1990;66:522.

24. Lloyd TR, Beekman RH. Transcatheter closure of atrial septal defects and persistent ductus arteriosus. In: Topol EJ, ed. Textbook of Interventional Cardiology. Philadelphia:W.B. Saunders Co. 1994, pp. 1298-1311. 